\title{
Programlanabilir lojik kontrolör (PLC) tabanlı iklim istasyonu için bitki su tüketimi hesap yazılımının geliştirilmesi
}

\author{
Development of crop water consumption calculation software for programmable \\ logic controller (PLC) based climate station
}

\section{Cafer GENÇOĞLAN ${ }^{1}$ (i), Selçuk USTA ${ }^{2}$ (i), Serpil GENÇOĞLAN ${ }^{1}{ }^{(i)}$, Ekin ŞARLI $^{3}$ (i)}

${ }^{1}$ Kahramanmaraş Sütçü İmam Üniversitesi, Ziraat Fakültesi, Biyosistem Mühendisliği Bölümü, 46040, Kahramanmaraş

${ }^{2}$ Van Yüzüncü Y1l Üniversitesi, Van Meslek Yüksekokulu, İnşaat Bölümü, 65090, Van

${ }^{3}$ Devlet Su İşleri 67. Şube Müdürlüğü, 33430, Mersin

Sorumlu yazar (Corresponding author): S. Usta, e-posta (e-mail): susta@yyu.edu.tr

Yazar(lar) e-posta (Author e-mail): gencoglan@ksu.edu.tr, sgencoglan@ksu.edu.tr, ekin.sarli@gmail.com

\section{MAKALE BILLIISİ}

Alınış tarihi 01 Ağustos 2019

Düzeltilme tarihi 30 Ağustos 2019

Kabul tarihi 05 Eylül 2019

\section{Anahtar Kelimeler:}

CODESYS-ST

$\mathrm{ET}_{\mathrm{o}}$

$\mathrm{ET}_{\mathrm{c}}$

İklim istasyonu

Penman monteith

\section{ÖZ}

Bu çalışmada; bazı iklim parametrelerini kullanarak FAO 56 Penman Monteith yöntemine göre günlük Referans evapotranspirasyon $\left(\mathrm{ET}_{\mathrm{o}}\right)$ miktarını hesaplayan, CODESYS-ST programlama dilinde bir iklim istasyonu yazılımının geliştirilmesi, bu yazılım kullanılarak misır (Zea mays L.) bitkisinin bitki su tüketiminin hesaplanması ve mevcut verilerle karşılaştırılması amaçlanmıştır. Çalışma, Kahramanmaraş ilinde Meteoroloji Genel Müdürlüğünden temin edilen 2018 yılı günlük iklim verileri ile yürütülmüştür. Yazılım, PLC PRG (PRG) programına ek olarak ET0 hesap (PRG), entegral (PRG) ve iklim_verileri $(\mathrm{PRG})$ alt programlarından oluşturulmuştur. İklim istasyonu yazılımı kullanılarak günlük $\mathrm{ET}_{\mathrm{o}}$ değerleri hesaplanmıştır. $\mathrm{Bu} \mathrm{ET}_{\mathrm{o}}$ değerleri, mısırın bitki büyüme katsayıları $\left(\mathrm{k}_{\mathrm{c}}\right)$ ile çarpılarak mısırın günlük bitki su tüketimi $\left(\mathrm{ET}_{\mathrm{c}}\right)$ belirlenmiș ve "Türkiye'de Sulanan Bitkilerin $\mathrm{Su}$ Tüketim Rehberi" ile karşılaştırılmıştır. Yazılımla hesaplanan $\mathrm{ET}_{\mathrm{c}}$ değerlerinin Rehberde verilen $\mathrm{ET}_{\mathrm{c}}$ değerlerinden olan sapma miktarının bir ifadesi olarak OMGH \%8.17, KOKH 0.55 olarak hesaplanmıştır. $\mathrm{ET}_{\mathrm{o}}$ ve $\mathrm{ET}_{\mathrm{c}}$ değerleri arasındaki ilişki $\mathrm{ET}_{\mathrm{c}}=2.1298 \mathrm{ET}_{\mathrm{o}}-6.2876$ $\left(\mathrm{R}^{2}=1\right)$ fonksiyonu ile ortaya koyulmuştur. Yazılımın Rehberle uyumlu olduğu, günlük $E T_{o}$ ve $\mathrm{ET}_{\mathrm{c}}$ hesaplamalarında kullanılabileceği sonucuna varılmıştır.

\section{ARTICLE INFO}

Received 01 August 2019

Received in revised form 30 August 2019

Accepted 05 September 2019

\section{Keywords:}

CODESYS-ST

$\mathrm{ET}_{\mathrm{o}}$

$\mathrm{ET}_{\mathrm{c}}$

Climate station

Penman monteith

\begin{abstract}
In this study; It is aimed to develop a climate station software in CODESYS-ST programming language which calculates daily Reference evapotranspiration $\left(\mathrm{ET}_{\mathrm{o}}\right)$ amount according to FAO 56 Penman Monteith method by using some climate parameters, calculating crop water consumption of maize (Zea mays L.) using this software and comparing with the available data. The study was carried out with daily climate data of Kahramanmaras Province in 2018 obtained from the General Directorate of Meteorology. The software is composed of ET0_account (PRG), integral (PRG) and climate_data (PRG) subprograms in addition to the PLC_PRG (PRG) program. Daily $\mathrm{ET}_{\mathrm{o}}$ values were calculated using climate station software. Maize daily water consumption $\left(\mathrm{ET}_{\mathrm{c}}\right.$ ) was obtained by multiplying $\mathrm{ET}_{\mathrm{o}}$ values with maize crop coefficients $\left(\mathrm{k}_{\mathrm{c}}\right)$ and compared with values of "Water Consumption Guide of the Irrigated Crops in Turkey". The values of MAPE and RMSE between $\mathrm{ET}_{\mathrm{c}}$ values calculated with the software and $\mathrm{ET}_{\mathrm{c}}$ values given in Guide were calculated as $8.17 \%$ and 0.55 . The relationship between $\mathrm{ET}_{\mathrm{o}}$ and $\mathrm{ET}_{\mathrm{c}}$ values was determined as $\mathrm{ET}_{\mathrm{c}}=2.1298 \mathrm{ET}_{\mathrm{o}}-6.2876\left(\mathrm{R}^{2}=1\right)$. It was concluded that the results of software was compatible with values of Guide and could be used for daily $\mathrm{ET}_{\mathrm{o}}$ and $\mathrm{ET}_{\mathrm{c}}$ calculations.
\end{abstract}




\section{Giriş}

Ülkemizin büyük bir bölümünün de içerisinde bulunduğu kurak-yarı kurak iklim bölgelerinde bitki su tüketimi (Evapotranspirasyon), sulama ve su yönetimi konuları büyük bir öneme sahiptir. Küresel 1sınmaya bağlı olarak gelişen iklim değişikliği ile su kaynaklarının gün geçtikçe azalması, buna karşın nüfusun ve dolayısıyla su talebinin gün geçtikte daha da artması mevcut su kaynaklarının tasarruflu kullanılmasını ve geleceğe dönük su yönetimi planlamalarının yapılmasını zorunlu kilmaktadir.

Tarım sektörü $\% 70$ oranla ülkemizde su tüketiminin en fazla olduğu sektördür. $\mathrm{Bu}$ sektörde su kaynaklarının sürdürülebilir bir biçimde kullanılmasını sağlamanın en doğru yolu, sulama programlaması yapılarak suyun bitkiye ne zaman ve ne miktarda verileceğinin belirlenmesidir. Bu nedenle, tarla koşullarında bitki su tüketimi ile ilgili kesin bilgilere ihtiyaç duyulmaktadır (Burman ve Pochop 1994; Akpolat 2011).

Bitki su tüketimi lizimetre ile doğrudan ölçülebildiği gibi bitki, toprak ve iklim özelliklerine dayalı olarak çok sayıda ampirik yöntemle tahmin edilebilmektedir. Lizimetrenin ekstra zaman ve işgücü kullanımı gerektirmesi nedeniyle daha çok tahmin yöntemleri tercih edilmektedir. Bu bağlamda en çok kullanılan yaklaşım, önce referans bir bitki (çim) için su tüketimini $\left(\mathrm{ET}_{\mathrm{o}}\right)$ tahmin etmek, sonra da bu değeri bitki büyüme katsayısı $\left(\mathrm{k}_{\mathrm{c}}\right)$ ile düzelterek bitki su tüketimini $\left(\mathrm{ET}_{\mathrm{c}}\right)$ elde etmektir (Doorenbos ve Pruitt 1977). Referans bitki su tüketimi $\left(\mathrm{ET}_{\mathrm{o}}\right)$ tahmininde kullanılan yöntemlerinin en önemlileri; Penman Monteith, Pan Evaporation, Hargreaves, Kimberly Penman ve Blaney Criddle yöntemleridir. Tarla koşullarında $\mathrm{ET}_{\mathrm{o}}$ miktarını belirlemek amacıyla en çok tercih edilen yöntemin geliştirilmiş FAO 56 Penman Monteith olduğu belirtilmektedir (Çetin ve ark. 2014; Koç ve Güner 2005).

$\mathrm{ET}_{\mathrm{o}}$ miktarını tahmin etmek amacıyla en yaygın kullanılan bilgisayar yazılımları DAILY ET (Hess 1996), DSS_ET (Bandyopadhyay ve ark. 2012), REF_ET (Allen 2015), CROPWAT (FAO 1992), ETo CALCULATOR (Raes 2012), IAM_ETo (Steduto ve Snyder 1998), ve ET0 (Gocic ve Trajkovic 2010) yazılımlarıdır. Bu yazılımların birçoğunda aylık ortalama iklim verileri kullanılarak, her ay için bir tane ortalama $\mathrm{ET}_{\mathrm{o}}$ değeri belirlenmektedir. Sulama programında ilgili ayın tüm günleri için aynı ortalama $\mathrm{ET}_{0}$ değeri dikkate alınmaktadır. Oysaki hassas sulama programlarında, her bir güne ait gerçek zamanlı iklim verileri ile hesaplanan günlük $\mathrm{ET}_{\mathrm{o}}$ değerlerinin kullanılması gerekmektedir (Jensen ve ark. 1990). Bu çalışma kapsamında geliştirilen yazılım ile gerçek zamanlı günlük iklim parametreleri iklim istasyonuna ölçtürülebilmekte ve bu parametreler kullanılarak günlük $\mathrm{ET}_{\mathrm{o}}$ miktarları tahmin edilebilmektedir.

Bitki su tüketiminin tahmin edilmesinde, genellikle çok sayıda iklim parametresi içeren karmaşı eşitlikler kullanılmaktadır. $\mathrm{Bu}$ eşitliklerde ihtiyaç duyulan iklim parametrelerinin birçoğu ülkemizde sadece şehir merkezlerinde devamlı ve düzenli olarak ölçülebilmektedir. Buna karşın tarımsal üretim faaliyetleri daha çok yerel düzeydeki kırsal alanlarda yürütülmektedir. Yerel düzeyde iklim verilerini ölçmek için portatif iklim istasyonları kullanılabilmektedir. Ancak bu iklim istasyonlarının satış bedelleri üreticilerin satın alma gücünün çok üzerindedir. Bu nedenle, yerli imkânlarla oluşturulacak iklim istasyonlarına ve bunların işletilmesinde kullanılacak yazılımların geliştirilmesine ihtiyaç duyulmaktadır.

$\mathrm{Bu}$ çalışmada, PLC tabanlı bir iklim istasyonunun işletilmesinde kullanılabilecek ve iklim istasyonunun ölçtüğü iklim parametrelerini kullanarak, FAO 56 Penman Monteith yöntemine göre gerçek zamanlı günlük $\mathrm{ET}_{\mathrm{o}}$ miktarlarını hesaplayabilecek bir iklim istasyonu yazılımının geliştirilmesi amaçlanmıştır. Yazılımı test etmek amacıyla "Türkiye'de Sulanan Bitkilerin Su Tüketim Rehberinden" faydalanılmıştır (TAGEM 2016). Kahramanmaraş iline ait 2018 y1lı günlük iklim verileri kullanılarak yazılımla hesaplanan $\mathrm{ET}_{\mathrm{o}}$ değerleri ile bu değerlere bağlı olarak mısır bitkisi için hesaplanan $\mathrm{ET}_{\mathrm{c}}$ değerleri Su Tüketim Rehberiyle karşılaştırılmıştır.

\section{Materyal ve Yöntem}

$\mathrm{Bu}$ çalışma, bitki su tüketiminin büyük bir öneme sahip olduğu kurak-yarı kurak iklim kuşağında yer alan Kahramanmaraş ilinde, Meteoroloji Genel Müdürlüğünden temin edilen 2018 yılı günlük iklim verileri ile yürütülmüştür. Kahramanmaraş İlinin rakımı $600 \mathrm{~m}$ olup, 37 $36^{\prime}$ kuzey, 36 ${ }^{\circ} 55^{\prime}$ doğu enlem ve boylamlarında bulunmaktadır. Ortalama hava s1caklığ $16.9^{\circ} \mathrm{C}$, oransal nem değeri \%58.34, günlük güneşlenme süresi 6.77 saat gün $^{-1}$ ve yıllık toplam yağış miktarı $725.4 \mathrm{~mm}$ düzeyindedir (DMİ 2018).

PLC kontrollü iklim istasyonuna günlük iklim verilerini ölçtüren ve bu verileri kullanarak günlük $\mathrm{ET}_{\mathrm{o}}$ miktarını hesaplayabilen bir yazılım geliştirmek amacıyla, ilk olarak Eşitlik 1 ile verilen FAO 56 Penman Monteith yöntemi doğrultusunda Şekil 1'de verilen akış diyagramı oluşturulmuştur (ASCE-EWRI 2004; Pereira ve ark. 2015). Akış diyagramına uygun olarak CODESYS-ST programlama dilinde bir yazılım hazırlanmıştır. Mısır (Zea mays L.) bitkisinin günlük $\mathrm{ET}_{\mathrm{c}}$ miktarlarını belirlemek amacıyla Eşitlik 2 kullanılmıştır.

$$
\mathrm{ET}_{\mathrm{o}}=\frac{0,408 \cdot \Delta \cdot\left(\mathrm{R}_{\mathrm{n}}-\mathrm{G}\right)+\gamma \frac{900}{\mathrm{~T}+273} \mathrm{U}_{2} \cdot\left(\mathrm{e}_{\mathrm{s}}-\mathrm{e}_{\mathrm{a}}\right)}{\Delta+\gamma \cdot\left(1+0,34 \cdot \mathrm{U}_{2}\right)}
$$

$$
\mathrm{ET}_{\mathrm{c}}=\mathrm{ET}_{\mathrm{o}} \cdot \mathrm{k}_{\mathrm{c}}
$$

PLC kontrollü iklim istasyonunun sıcaklık $(\mathrm{T})$ ve oransal nemi $\left(\mathrm{R}_{\mathrm{H}}\right) 24$ saatlik periyotlar halinde her saat başı, solar radyasyon $\left(R_{S}\right)$ ve $2 \mathrm{~m}$ yükseklikteki rüzgâr hızını $\left(\mathrm{U}_{2}\right)$ ise her 30 dakikada bir ölçerek diziye ve SD karta kaydetmesi öngörülmüştür.

Yazılımın kullanılabilirliği Kahramanmaraş koşullarında yetiştirildiği varsayılan mısır (Zea mays L.) bitkisi üzerinde test edilmiştir. Yazılımla hesaplanan günlük $\mathrm{ET}_{0}$ değerleri, mısırın bitki büyüme katsayıları $\left(\mathrm{k}_{\mathrm{c}}\right)$ ile çarpılarak, mısırın günlük $\mathrm{ET}_{\mathrm{c}}$ değerleri elde edilmiştir. Yazılımla hesaplanan $\mathrm{ET}_{\mathrm{o}}$ ve $\mathrm{ET}_{\mathrm{c}}$ değerleri, "Türkiye'de Sulanan Bitkilerin $\mathrm{Su}$ Tüketim Rehberinde" Kahramanmaraş için verilen $\mathrm{ET}_{\mathrm{o}}$ ve $\mathrm{ET}_{\mathrm{c}}$ değerleri ile karşılaştırılmıştır (TAGEM 2016). Rehberde belirtilen bitki su tüketimi değerleri Çizelge 1'de verilmiştir. Mısırın ekim tarihi 1 Nisan, hasat tarihi ise 6 Eylül olarak dikkate alınmıştır. Vejetasyon dönemi boyunca kc katsayısının değişimi Şekil 2'de gösterilmiştir (TAGEM 2016).

İklim istasyonu yazılımı ile hesaplanan $\mathrm{ET}_{\text {o_yazılım ve }}$ $\mathrm{ET}_{\mathrm{c}_{\text {_yazllum }}}$ değerlerinin Rehberde verilen $\mathrm{ET}_{\text {__rehber }}$ ve $\mathrm{ET}_{\mathrm{C}_{\text {_rehber }}}$ değerlerinden olan sapmasının bir ifadesi olarak; mutlak hata $(\mathrm{MH})$, ortalama mutlak hata $(\mathrm{OMH})$, ortalama mutlak göreceli hata oranı $(\mathrm{OMGH})$ ve karekök ortalama karesel hata miktarı (KOKH) dikkate alınmıştır. Bu hata miktarları Eşitlik 3, 4, 5 ve 6 kullanılarak belirlenmiştir (Ünver ve Gamgam 1999). 
$\mathrm{MH}=\left|\mathrm{ET}_{\mathrm{o} \_ \text {rehber }}-\mathrm{ET}_{\text {o_yazilım }}\right|$
$\mathrm{OMH}=\frac{1}{\mathrm{n}} \sum_{\mathrm{i}=1}^{\mathrm{n}}\left|\mathrm{ET}_{\mathrm{o} \_ \text {rehber }}-\mathrm{ET}_{\text {o_yazilım }}\right|$

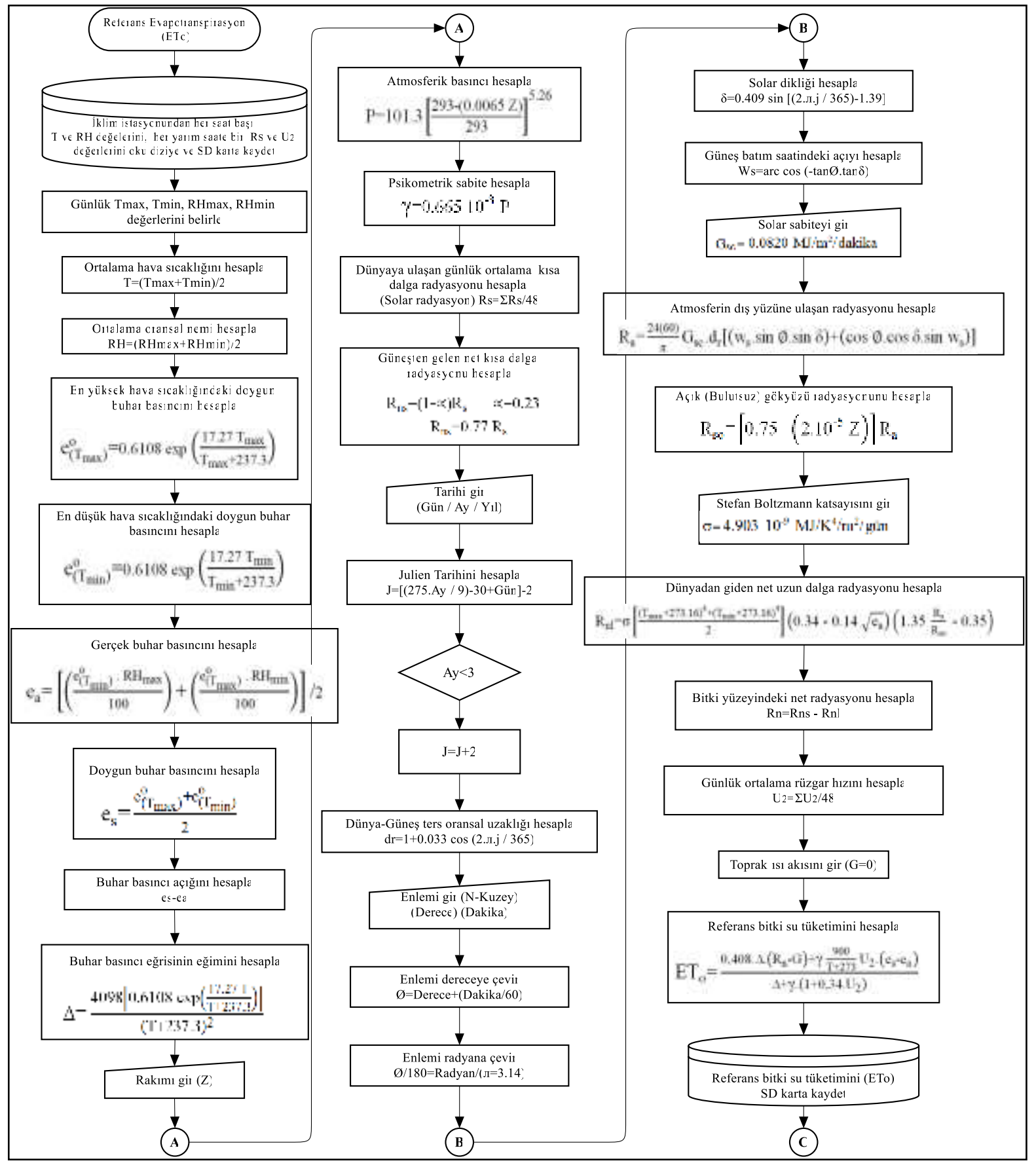

Şekil 1. İklim istasyonu yazılımı için oluşturulan akış diyagramı.

Figure 1. Flow chart for climate station software.

Çizelge 1. Kahramanmaraş için su tüketim rehberinde verilen referans evapotranspirasyon $\left(\mathrm{ET}_{\mathrm{o}}\right)$ ve evapotranspiraston $\left(\mathrm{ET}_{\mathfrak{c}}\right) \mathrm{değerleri}$

Table 1. Reference evapotranspiration ( $\left.E T_{0}\right)$ and evapotranspiration $\left(E T_{c}\right)$ values given in the guide for Kahramanmaras.

\begin{tabular}{lcccccccccccc}
\hline Aylar & 1 & 2 & 3 & 4 & 5 & 6 & 7 & 8 & 9 & 10 & 11 & 12 \\
\hline Referans evapotranspirasyon $\left(\mathrm{mm} \mathrm{gün}^{-1}\right)$ & 1.41 & 1.97 & 3.22 & 4.84 & 5.83 & 7.44 & 8.06 & 7.72 & 6.42 & 3.96 & 1.87 & 1.21 \\
Evapotranspirasyon $\left(\mathrm{mm} \mathrm{gün}^{-1}\right)$ & - & - & - & 1.74 & 3.90 & 7.45 & 8.52 & 6.60 & - & - & - & - \\
\hline
\end{tabular}




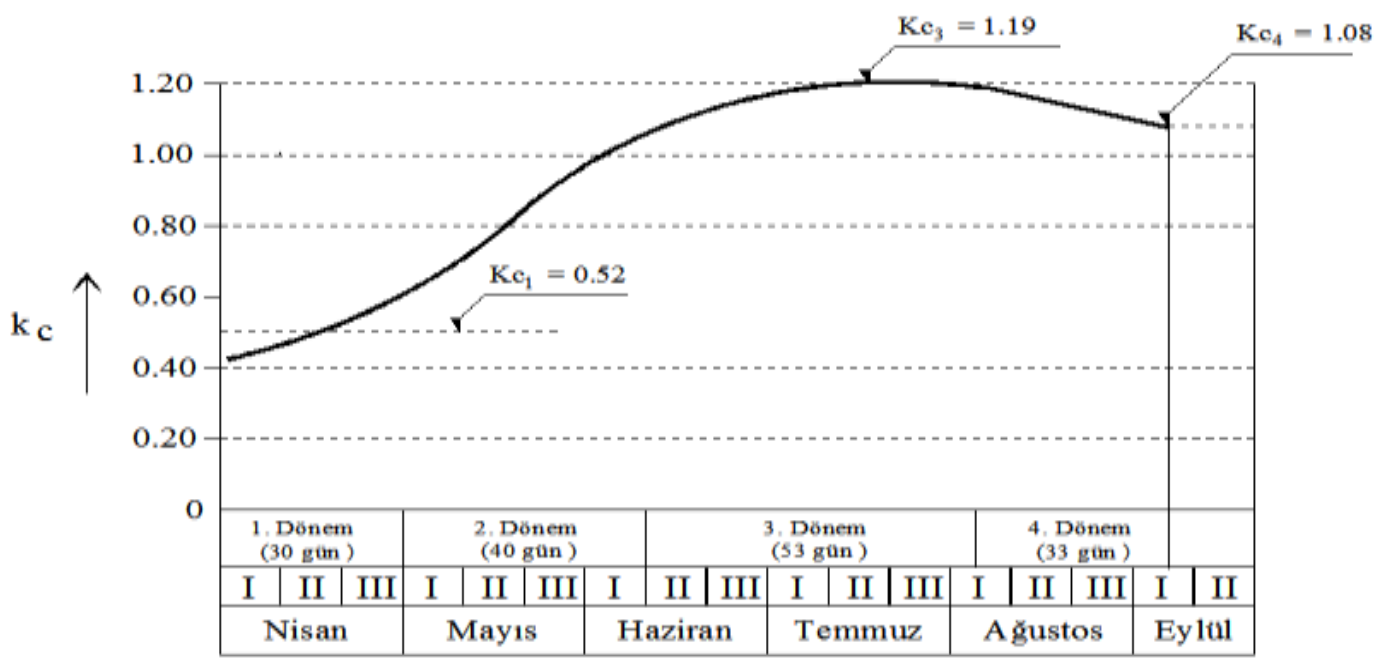

Şekil 2. Kahramanmaraş koşullarında mısır bitkisinin $\mathrm{k}_{\mathrm{c}}$ eğrisi.

Figure 2. $k_{c}$ curve of maize under the Kahramanmaras conditions.

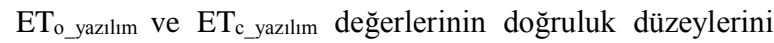
belirlemek amacıyla üç farklı kriter dikkate alınmıştır. Birinci kritere göre; OMGH değerleri \%10'un altında ise yazılım "çok iyi", \%10 ile \%20 arasında ise "iyi", \%20 ile \%50 arasında ise "kabul edilebilir" ve \%50'nin üzerinde ise "yanlış ve hatalı" olarak değerlendirilmiştir (Lewis 1982). İkinci kritere göre; OMGH değerleri \%10'un altında ise yazılım "yüksek doğruluk" derecesinde, \%10 ile \%20 arasında ise "doğru" olarak değerlendirilmiştir (Witt ve Witt 1992). Üçüncü kritere göre ise; $\mathrm{KOKH}$ değerleri dikkate alınmıştır. $\mathrm{Bu}$ değerlerin sıfıra yakınlığı, yazılımla hesaplanan $\mathrm{ET}_{\text {o_yazılım }}$ ve $\mathrm{ET}_{\mathrm{c}_{\text {_yazı }} \text { _lm }}$ değerlerinin kıstas olarak dikkate alınan $\mathrm{ET}_{\mathrm{o}_{-} \text {rehber }} \mathrm{ve} \mathrm{ET}_{\mathrm{c}_{\text {_rehber }}}$ değerlerine olan yakınlığını ifade etmektedir. KOKH değerleri ne kadar sıfıra yakın ise yazılımın doğruluk düzeyi o kadar yüksek olmaktadır (Willmott 1982).

\section{Bulgular ve Tartışma}

Günlük hava sıcaklığı, oransal nem, solar radyasyon ve rüzgâr hızı parametrelerini iklim istasyonuna ölçtüren, bu parametreleri kullanarak günlük $\mathrm{ET}_{\mathrm{o}}$ miktarını hesaplayan bir iklim istasyonu yazılımı hazırlanmıştır. Program Organizasyon Birimi (POU) altında PLC_PRG (PRG) ana programına ek olarak iklim_verileri (PRG), ET0_hesap (PRG), entegral (PRG) alt programları ve write_sd_card (FB) fonksiyon bloğu yazılmıştır. İklim_verileri (PRG) programı altına tarih_donusum isimli bir aksiyon (action) tanımlanmıștır. WORD değişkeni olarak tanımlanan yıl (act_y1l), BYTE değişkeni olarak tanımlanan ay (act_mounth), gün (act_day), saat (act_hour), dakika (act_min) ve INT değișkeni olarak tanımlanan minimum sicaklık (Min_Sic_S) ile maksimum sicaklık (Max_Sic_S) bu aksiyon içerisinde STRING değişkenlere dönüştürülmüşşür. Programların yerel (var) değişkenleri kendi içerisinde tanımlanmıștır.

Yazılım kapsamında hazırlanan iklim_verileri (PRG) ve entegral (PRG) programları sırasıyla Çizelge 2 ve Çizelge 3'de verilmiştir. Öncelikle iklim_verileri (PRG) programına ait yerel (var) değişkenleri tanımlanmıştır. Daha sonra CASE step OF komutu kullanılarak iklim istasyonunun iklim parametrelerini ölçmesi sağlanmış ve bu verilere bağlı olarak günlük $\mathrm{ET}_{\mathrm{o}}$ hesaplatılmıştır. CASE deyiminin ii değişkeni 0 ile 40 arasında değişmiştir. $\mathrm{ii}=0$ başlangıç aşamasında R_TRIG_iklim_veri tetikleyicisi kullanılarak; hava sicaklığı ve oransal nem parametrelerinin saatlik olarak ölçüleceği öngörülmüştür. Sensörün her saatin 59.dakikasının 10.saniyesinde çıkış vermesi planlanmıştır. Sensör çıkış verdiğinde CASE deyimi ii= 10 adımına yönlendirilmiştir. $\mathrm{Bu}$ adımda tarih_donusum isimli aksiyon (action) kullanılarak ölçüm tarihi STRING değişkene dönüştürülmüş ve hava sıcaklığı verisine "Sicaklik", oransal nem verisine "Oran_Nem" değişkeni atanmıştır. R TRIG_oku tetikleyicisi kullanılarak, saatlik ölçülen hava sıcaklığı ve oransal nem verileri günün 23. saatinin 59. dakikasının 58. saniyesinde büyükten küçüğe doğru sıralanmıştır. CASE deyimi, ii=20 adımına yönlendirilerek ortalama hava sıcaklığı (Ort_T) ve ortalama oransal nem Ort_RH değerleri hesaplanmıştır. iklim_verileri (PRG) alt programının devamı olarak hazırlanan ET0_hesap (PRG) alt programı ile günlük $\mathrm{ET}_{\mathrm{o}}$ miktarı belirlenmiştir. Tüm veriler sifirlanarak CASE deyimi $i \mathrm{i}=30$ adımına yönlendirilmiştir. Bu adımda gün, ay, yıl, maksimum hava sıcaklığ1 ve minimum hava sıcaklığ 1 string değerleri aralarına noktalı virgül koyularak, tarih_donusum isimli aksiyon vasıtasıyla birleştirilmiş ve CASE deyimi ii $=40$ adımına yönlendirilmiştir. $\mathrm{Bu}$ adımda veriler write_sd_card (FB) fonksiyon blok yazılımı yardımıyla SD karta kaydedilmiş ve CASE deyimi ii=0 adımına yönlendirilmiştir. Günlük toplam solar radyasyon (INTEGRAL_Rs) ve günlük toplam rüzgâr hızı değerlerini (INTEGRAL_Ruz_Hiz) ölçmek amaciyla entegral (PRG) alt programı hazırlanmış̧ır.

Geliştirilen iklim istasyonu yazılımı ve 2018 yılı günlük iklim verileri kullanılarak, misır bitkisinin vejetasyon dönemi (Nisan-Ağustos) boyunca günlük $\mathrm{ET}_{\mathrm{o}}$ ve $\mathrm{ET}_{\mathrm{c}}$ miktarları belirlenmiștir. Elde edilen $\mathrm{ET}_{\mathrm{o}}$ ve $\mathrm{ET}_{\mathrm{c}}$ değerleri ile iklim verilerinin aylık ortalama değerleri Çizelge 4'te verilmiştir.

Yazılımla hesaplanan günlük $\mathrm{ET}_{\mathrm{o}}$ ve $\mathrm{ET}_{\mathrm{c}}$ değerleri, $\mathrm{Su}$ Tüketim Rehberinde Kahramanmaraş için verilen değerlerle karşılaştırılmıştır. $\mathrm{ET}_{\mathrm{o}}$ ve $\mathrm{ET}_{\mathrm{c}}$ değerlerinin aylık değişimleri Şekil 3'de gösterilmiştir. Yazılımla hesaplanan $\mathrm{ET}_{0}$ değerlerinin Rehberde verilen $\mathrm{ET}_{0}$ değerlerinden olan sapmasının bir ifadesi olarak; OMH 1.30 mm gün ${ }^{-1}$, OMGH oranı $\% 19.28$ ve $\mathrm{KOKH}$ değeri $1.19 \mathrm{~mm}$ gün ${ }^{-1}$ olarak belirlenmiştir. $\mathrm{ET}_{\mathrm{c}}$ değerleri için yapılan karşıllaştırmaya göre ise $\mathrm{OMH} 0.48 \mathrm{~mm}$ gün ${ }^{-1}$, OMGH oranı \%8.17 ve KOKH değeri $0.55 \mathrm{~mm}$ gün $^{-1}$ olarak belirlenmiştir. Mısırın mevsimlik su tüketimi yazılımla 854.55 $\mathrm{mm}$, Rehber verilerine göre ise $856 \mathrm{~mm}$ olarak belirlenmiştir. 
Çizelge 2. İklim_verileri (PRG) alt programı.

Table 2. Climate_data (PRG) sub program.

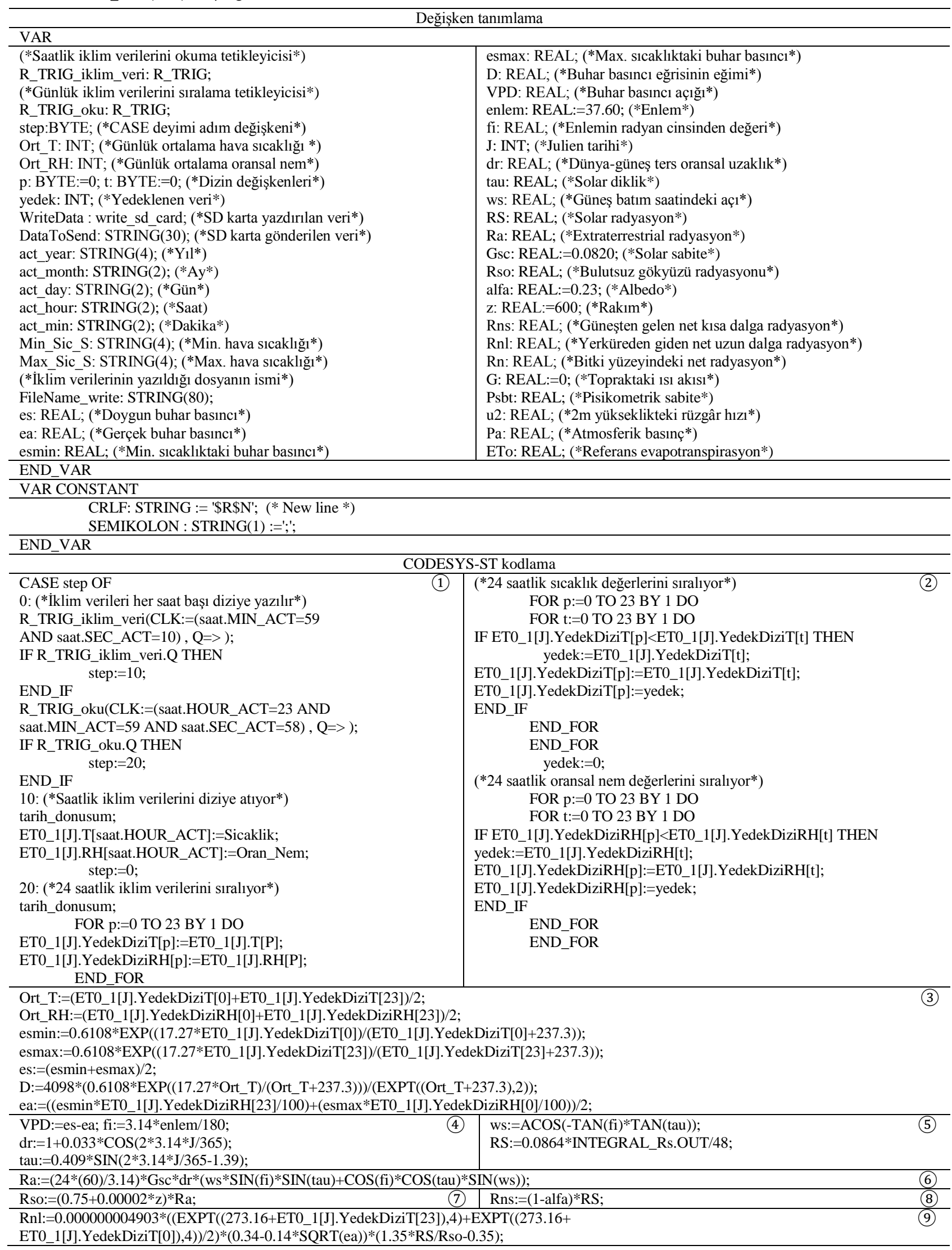


Çizelge 2 (devamı). İklim_verileri (PRG) alt programı.

Table 2 (continued). Climate_data (PRG) sub program.

\begin{tabular}{|c|c|c|}
\hline $\begin{array}{l}\text { Rn:=Rns-Rnl; } \\
\mathrm{Pa}:=101.3 * \operatorname{EXPT}\left(\left(293-0.0065^{*} \mathrm{z}\right) / 293,5.26\right) ;\end{array}$ & $\begin{array}{l}\text { Psbt:=0.000665*Pa; } \\
\text { u2:=INTEGRAL_Ruz_Hiz.OUT/48; }\end{array}$ & (11) \\
\hline \multicolumn{2}{|c|}{ ETo:=(0.408*D*(Rn-G)+(Psbt*900*u2/(Ort_T+273))*(es-ea))/(D+Psbt*(1+0.34*u2)); } & (12) \\
\hline $\begin{array}{l}\text { reset1:=TRUE; } \\
\text { step:=30; } \\
\text { 30: (*Verileri SD karta gönderiyor*) } \\
\quad \text { reset1:=FALSE; } \\
\text { tarih_donusum; } \\
\text { DataToSend :=CONCAT(act_day, '-'); } \\
\text { DataToSend := CONCAT(DataToSend, act_month); } \\
\text { DataToSend := CONCAT(DataToSend, '-'); } \\
\text { DataToSend }:=\text { CONCAT(DataToSend, act_year); }\end{array}$ & $\begin{array}{l}\text { DataToSend }:=\text { CONCAT(DataToSend, SEMIKOLON); } \\
\text { DataToSend }:=\text { CONCAT(DataToSend, Min_Sic_S); } \\
\text { DataToSend }:=\text { CONCAT(DataToSend, SEMIKOLON); } \\
\text { DataToSend }:=\text { CONCAT(DataToSend, Max_Sic_S); } \\
\text { DataToSend }:=\text { CONCAT(DataToSend, SEMIKOLON); } \\
\text { DataToSend }:=\text { CONCAT(DataToSend, GDG_S); } \\
\text { DataToSend }:=\text { CONCAT(DataToSend, CRLF); } \\
\text { fileName_write:='sdcard/Min_Max.csv'; } \\
\quad \text { step }:=40 ;\end{array}$ & (14) \\
\hline \multicolumn{2}{|c|}{$\begin{array}{l}\text { 40: }(* \text { Verileri SD karta yazdırıyor*) } \\
\text { WriteData(enable:=TRUE, sFileName:=fileName_write, strData:= DataToSend); }\end{array}$} & (15) \\
\hline $\begin{array}{l}\text { IF WriteData.done AND NOT WriteData.error } \\
\text { THEN } \\
\text { WriteData(enable:= FALSE); } \\
\text { DataToSend:=' '; } \\
\quad \text { step:=0; }\end{array}$ & $\begin{array}{l}\text { ELSE } \\
\text { END_IF } \quad \text { step:=40; } \\
\text { END_CASE }\end{array}$ & (17) \\
\hline
\end{tabular}

Çizelge 3. Entegral (PRG) alt programı.

Table 3. Integral (PRG) sub program.

\begin{tabular}{|c|c|}
\hline \multicolumn{2}{|c|}{ CODESYS-ST kodlama } \\
\hline \multicolumn{2}{|c|}{$\begin{array}{l}\text { saat }(\mathrm{EN}:=\text { TRUE); } \\
\text { IF saat.HOUR_ACT }>=0 \text { AND saat.HOUR_ACT }<=23 \text { AND saat.MIN_ACT }>=0 \text { AND saat.MIN_ACT }<=30 \text { AND saat.SEC_ACT }>=0 \text { AND } \\
\text { saat.SEC_ACT }<=56 \text { THEN }\end{array}$} \\
\hline $\begin{array}{l}\text { INTEGRAL_Rs( } \\
\text { IN:=Solar_R } \\
\text { TM:=1000, } \\
\text { RESET:=reset } 1 \\
\text { OUT }=> \\
\text { OVERFLOW }=>) ;\end{array}$ & $\begin{array}{l}\text { INTEGRAL_Ruz_Hiz( } \\
\text { IN:=RuzgarHiz, } \\
\text { TM:=1000, } \\
\text { RESET:=reset } 1 \\
\text { OUT }=>\text {, } \\
\text { OVERFLOW }=>) ;\end{array}$ \\
\hline END_IF & (4) \\
\hline
\end{tabular}

Çizelge 4. Referans evapotranspirasyon $\left(\mathrm{ET}_{\mathrm{o}}\right)$, evapotranspirasyon $\left(\mathrm{ET}_{\mathrm{c}}\right)$ ve iklim verilerinin aylik ortalamaları.

Table 4. Monthly average of reference evapotranspiration ( $\left.E T_{0}\right)$, evapotranspiration $\left(E T_{c}\right.$ ) and climate data.

\begin{tabular}{lcccc}
\hline Aylar & Nisan & Mayıs & Haziran & Temmuz \\
\hline Hava sıcaklı̆̆ $\left({ }^{\circ} \mathrm{C}\right)$ & 18.77 & 22.22 & 26.16 & 29.40 \\
Oransal nem $(\%)$ & 45.90 & 51.42 & 47.50 & 43.95 \\
2 m yükseklikteki rüzgâr hızı $\left(\mathrm{m} \mathrm{s}^{-1}\right)$ & 1.03 & 1.12 & 1.56 & 4.07 \\
Solar radyasyon $\left(\mathrm{MJ} \mathrm{m}^{-2}\right.$ gün $\left.^{-1}\right)$ & 17.90 & 21.30 & 24.70 & 1.37 \\
Referans evapotranspirasyon $\left(\mathrm{mm} \mathrm{gün}^{-1}\right)$ & 3.80 & 4.71 & 6.11 & 24.40 \\
Bitki büyüme katsayısı & 0.50 & 0.77 & 1.07 & 6.65 \\
Evapotranspirasyon $\left(\mathrm{mm} \mathrm{gün}^{-1}\right)$ & 1.88 & 3.64 & 6.51 & 1.19 \\
\hline
\end{tabular}

Yazılımla hesaplanan $\mathrm{ET}_{\mathrm{o}}$ değerleri için elde edilen $\mathrm{OMGH}$ değeri (\%19.28) dikkate alınarak birinci kritere göre; yazılımın "iyi", ikinci kritere göre ise "doğru" sınıfında yer aldığı belirlenmiştir. $\mathrm{ET}_{\mathrm{c}}$ değerleri için elde edilen $\mathrm{OMGH}$ değeri (\%8.17) dikkate alınarak birinci kritere göre; yazılımın "çok iyi" sinıfinda yer aldığı, ikinci kritere göre ise "yüksek doğruluk" derecesine sahip olduğu belirlenmiştir. Üçüncü kritere göre ise, KOKH değerlerinin (1.19-0.55) sifira yakınlı dereceleri dikkate alındığında yazılımın doğruluk düzeyinin yüksek olduğu görülmektedir.

Rehberde, $\mathrm{ET}_{\mathrm{o}}$ değerleri iklim verilerinin aylık uzun y1llar ortalamaları kullanılarak belirlenmiştir. Bu çalışmada ise 2018 y1lı günlük iklim verileri ile belirlenmiştir. Tek yıllık iklim verileri uzun yıllar ortalaması iklim verilerine göre farkl1lıklar gösterebilmektedir. $\mathrm{Bu}$ nedenle, yazilımla hesaplanan $\mathrm{ET}_{\mathrm{o}}$ değerleri için belirlenen hata miktarları, $\mathrm{ET}_{\mathrm{c}}$ değerleri için belirlenen hata miktarlarından daha büyük elde edilmiştir.
Yazılımla hesaplanan $\mathrm{ET}_{\mathrm{c}}$ değerlerindeki değişimin \%100’ü $\left(\mathrm{R}^{2}=1\right)$ yazılımla hesaplanan $\mathrm{ET}_{\mathrm{o}}$ değerleri ile açıklanabilmektedir. Rehberden alınan $\mathrm{ET}_{\mathrm{c}}$ değerlerindeki değişimin ise \%96's1 $\left(\mathrm{R}^{2}=0.96\right)$ Rehberdeki $\mathrm{ET}_{0}$ değerleri ile açıklanabilmektedir. Yazılımla hesaplanan değerlerin ilişki düzeyi daha yüksek elde edilmiştir (Şekil 4).

Yazılımla Kahramanmaraş koşullarında mısırın mevsimlik su tüketimi $854.55 \mathrm{~mm}$ olarak elde dilmiştir. Benzer iklim koşullarına sahip bazı yörelerde mısır için yürütülen çalışmalarda elde edilen mevsimlik su tüketimi değerleri; Uçak ve ark. (2010), tarafindan 2008-2009 yılları arasinda Adana koşullarında $771.2 \mathrm{~mm}$; Kırnak ve ark. (2003), tarafindan 19992000 yılları arasında Harran Ovası koşullarında $1320 \mathrm{~mm}$; Gençoğlan ve Yazar (1996), tarafından Çukurova koşullarında $999 \mathrm{~mm}$ olarak belirlenmiştir. Bu çalışma kapsamında elde edilen mevsimlik su tüketimi miktarı ile söz konusu araştırmacıların elde ettikleri değerler arasında paralellik bulunmaktadir. 


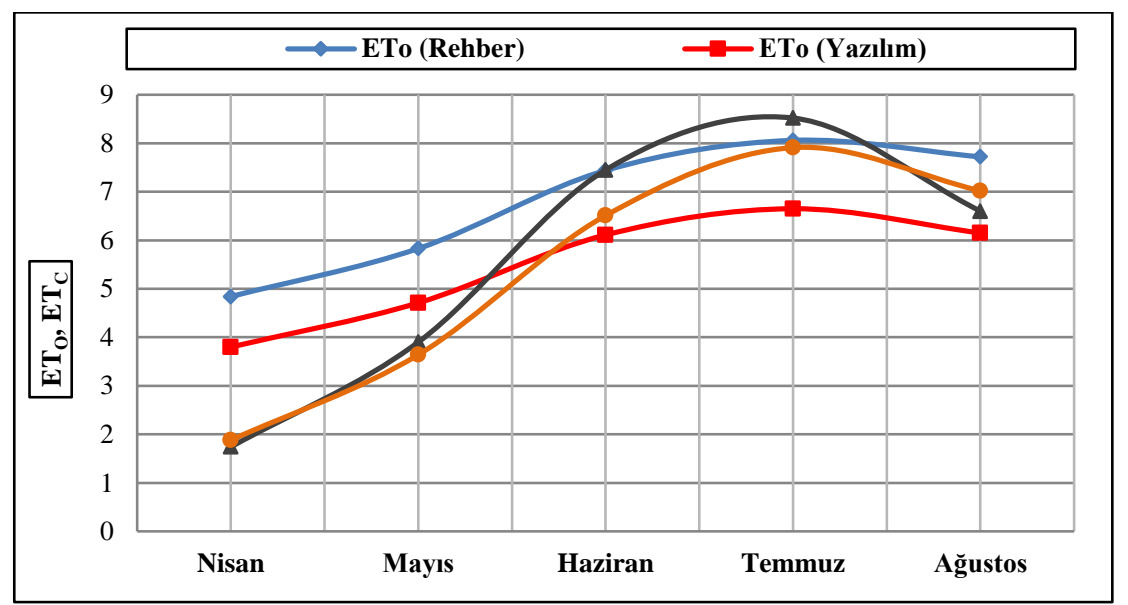

Şekil 3. $\mathrm{ET}_{\mathrm{o}}$ ve $\mathrm{ET}_{\mathrm{c}}$ değerlerinin aylık değişim grafikleri.

Figure 3. Monthly graphs of $\mathrm{ET}_{\mathrm{o}}$ and $\mathrm{ET}_{\mathrm{c}}$ values.

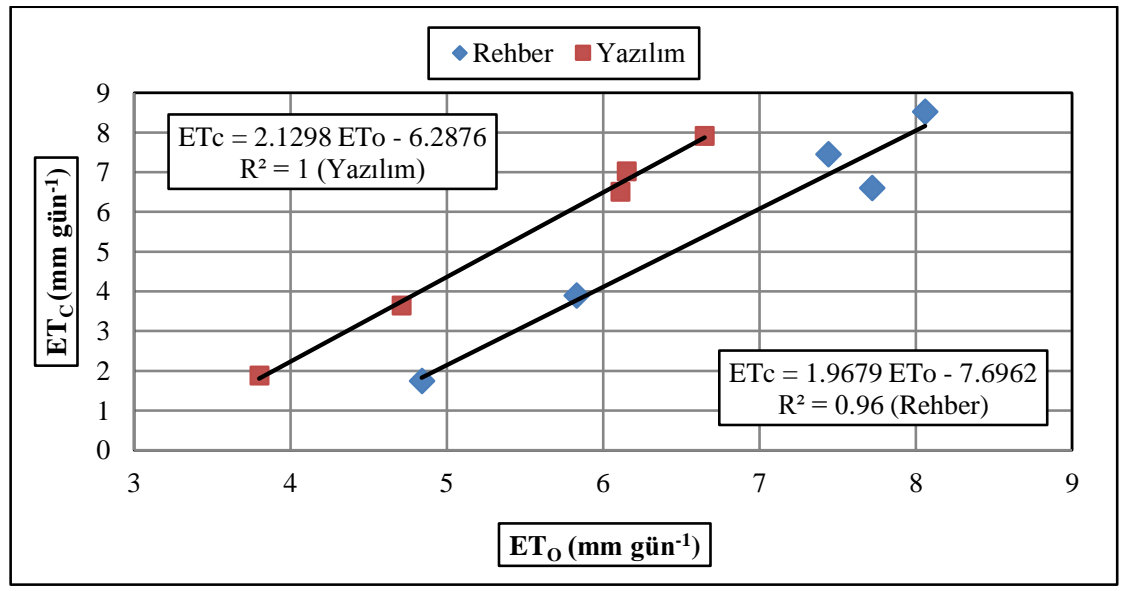

Şekil 4. $\mathrm{ET}_{\mathrm{c}}$ ve $\mathrm{ET}_{\mathrm{o}}$ değerleri arasındaki istatistikî ilişsi düzeyi.

Figure 4. Statistical relationship between $\mathrm{ET}_{\mathrm{c}}$ and $\mathrm{ET}_{\mathrm{o}}$ values.

\section{Sonuç}

Bu çalışmada; günlük $\mathrm{ET}_{\mathrm{o}}$ hesabında ihtiyaç duyulan iklim parametrelerin ölçülmesinde kullanılacak PLC tabanlı iklim istasyonunun kontrol edilmesini sağlayan ve bu iklim istasyonunun ölçtüğü iklim verilerini kullanarak FAO 56 Penman Monteith yöntemine göre $\mathrm{ET}_{\mathrm{o}}$ miktarını hesaplayan bir iklim istasyonu yazılımı geliştirilmiştir.

Kahramanmaraş koşullarında yazılımla hesaplanan ETo değerlerinin, "Türkiye'de Sulanan Bitkilerin $\mathrm{Su}$ Tüketim Rehberinde" verilen değerlerden olan sapma miktarının bir ifadesi olarak, OMGH \%19.28 ve KOKH 1.19 olarak belirlenmiştir. Mısır için yazılımla hesaplanan $\mathrm{ET}_{\mathrm{c}}$ değerlerinin, Rehberde verilen değerlerden olan sapma miktarının bir ifadesi olarak, OMGH \%8.17 ve KOKH 0.55 olarak belirlenmiştir.

Yazılımla hesaplanan $\mathrm{ET}_{\mathrm{o}}$ ve $\mathrm{ET}_{\mathrm{c}}$ değerleri arasındaki uyum $\% 100\left(\mathrm{R}^{2}=1\right)$, Su Tüketim Rehberinde Kahramanmaraş için verilen $\mathrm{ET}_{\mathrm{o}}$ ve $\mathrm{ET}_{\mathrm{c}}$ değerleri arasındaki uyum ise \%96 $\left(\mathrm{R}^{2}=0.96\right)$ olarak belirlenmiştir. Yazılımın genel olarak Rehberle uyumlu olduğu, günlük $\mathrm{ET}_{\mathrm{o}}$ ve $\mathrm{ET}_{\mathrm{c}}$ tahmininde kullanılabileceği sonucuna varılmıştır.

\section{Kaynaklar}

Akpolat A (2011) Mikrometeorolojik ve lizimetre yöntemleriyle belirlenen buğday bitki su tüketimlerinin karşılaştırılması. Yüksek Lisans Tezi, Çukurova Üniversitesi Fen Bilimleri Enstitüsü, Adana.

Allen RG (2015) REF-ET: Reference Evapotranspıration Calculation Software for FAO and ASCE Standardized Equations. User Manuel, University of Idaho.

TAGEM (2016) Türkiye'de Sulanan Bitkilerin Bitki Su Tüketimi Rehberi. T.C. Gıda, Tarım ve Hayvancılık Bakanlığı Tarımsal Araştırmalar ve Politikalar Genel Müdürlüğü Yayınları, Ankara.

ASCE-EWRI (2004) The ASCE Standardized Reference Evapotranspiration Equation. Technical Committee Report to the Environmental and Water Resources Institute of the American Society of Civil Engineers from the Task Committee on Standardization of Reference Evapotranspiration, USA.

Bandyopadhyay A, Bhadra A, Swarnakar RK, Raghuwanshi NS, Singh $\mathrm{R}$ (2012) Estimation of reference $\mathrm{ET}_{\mathrm{o}}$ using a user-friendly decision support system: DSS_ET. Agricultural and Forest Meteorology 154-155: 19-29.

Burman RD, Pochop LO (1994) Evaporation, evapotranspiration and climatic data. Development in Atmospheric Science, Elsevier, The Netherlands 22: 278. 
Çetin Ö, Köksal ES, Yıldırım YE, Özaydın KA (2014) Türkiye'de su tüketim rehberi çalışmaları kapsamında bitki su tüketimi ve bitki katsayılarının elde edilmesi. 12. Kültürteknik Sempozyumu Cilt 2, Tekirdağ, s. 40-45.

DMİ (2018) Kahramanmaraş İli 1930-2018 yılları arası aylık ortalama iklim verileri ve 2018 yılı günlük iklim verileri. Devlet Meteoroloji İşleri Genel Müdürlüğü.

Doorenbos J, Pruitt WO (1977) Crop Water Requirements, FAO Irrigation and Drainage Paper No. 24, Rome.

FAO (1992) CROPWAT-A Computer Program for Irrigation Planning and Management, FAO Irrigation and Drainage Paper No. 46, Rome.

Gençoğlan C, Yazar A (1996) Kısıntılı su uygulamalarının mısır verimine ve su kullanım randımanına etkileri. Turkish Journal of Agriculture and Forestry 23(1999): 233-241.

Gocic M, Trajkovic S (2010) Software for estimating reference evapotranspiration using limited weather Data. Computersand Electronics in Agriculture 71: 158-162.

Hess TM (1996) Potential Evapotranspiration [DAILY ET]. Silsoe College, UK.

Jensen ME, Burman RD, Allen RG (1990) Evapotranspiration and Irrigation Water Requirements. ASCE Manuals and Reports on Eng. Practice No: 70, ASCE, USA.

Kırnak H, Gençoğlan C, Değirmenci H (2003) Harran Ovası koşullarında kısıntılı sulamanın II. ürün mısır verimine ve bitki gelişimine etkisi. Atatürk Üniversitesi Ziraat Fakültesi Dergisi 34(2): 117-123.
Koç AC, Güner Ü (2005) Mevcut sulama projelerinin FAO kriterleriyle yeniden değerlendirilmesi: Tavas Ovası örneği. Dumlupınar Üniversitesi Fen Bilimleri Enstitüsü Dergisi 9: 93-106.

Lewis Colin D (1982) Industrialand Business Forecasting Methods. Butterworths Publishing, London.

Pereira LS, Allen RG, Smith M, Raesda DR (2015) Crop evapotranspiration estimation with FAO 56: Past and future. Agricultural Water Management 147: 4-20.

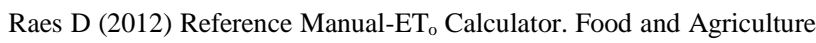
Organization of the United Nations Land and Water Division, Paper 37.

Steduto P, Snyder RL (1998) IAM_ET o software program and user's guide. Options Méditerranéennes: Série B Etudes et Recherches 20: 1-64.

Uçak AB, Değirmenci H, Gençoğlan C, Uçan K, Aykanat S, Karaca ÖF (2010) Misır bitkisinde farklı gelişme dönemlerinde su stresinin verime etkisi. I. Ulusal Tarımsal Yapılar ve Sulama Sempozyumu Cilt 2, Kahramanmaraş, s. 777-789.

Ünver Ö, Gamgam H (1999) Uygulamalı İstatistik Yöntemler. Siyasal Kitabevi, Ankara.

Willmott CJ (1982) Some comments on the evaluation of model performance. Bulletion of the American Meteorological Society 63: 1309-1313.

Witt SF, Witt CA (1992) Modeling and Forecasting Demand in Tourism. Academic Press, London. 